Article

\title{
Effect of a DC Stray Current on the Corrosion of X80 Pipeline Steel and the Cathodic Disbondment Behavior of the Protective 3PE Coating in 3.5\% $\mathrm{NaCl}$ Solution
}

\author{
Xinhua Wang, Zuquan Wang, Yingchun Chen *, Xuting Song and Yong Yang \\ College of Mechanical Engineering and Applied Electronics Technology, Beijing University of Technology, \\ Beijing 100124, China; wangxinhua@bjut.edu.cn (X.W.); 2534005625@emails.bjut.edu.cn (Z.W.); \\ 18811521053@emails.bjut.edu.cn (X.S.); yangyong-jd@emails.bjut.edu.cn (Y.Y.) \\ * Correspondence: yingchun.c@bjut.edu.cn
}

Received: 5 November 2018; Accepted: 27 December 2018; Published: 7 January 2019

\begin{abstract}
The influence of a direct current (DC) stray current on the corrosion and cathodic disbondment of $\mathrm{X} 80$ steel coated with a polyethylene (3PE) coating in $3.5 \% \mathrm{NaCl}$ solution was studied by immersion experiments, electrochemical tests, three-dimensional microscopy, and a surface analysis. The results showed that the potential of the X80 steel sample shifts under the direct current. After $100 \mathrm{~A} / \mathrm{m}^{2} \mathrm{DC}$ interference was applied, the potential of the sample in the anode region positively shifted from -0.68 to $-0.43 \mathrm{~V}$. At the same time, the sample in the cathode region negatively shifted to $-1.45 \mathrm{~V}$. Under the DC anode action, the X80 steel corrosion exhibited no passivation and followed Faraday's law of electrolysis, in which the corrosion rate is proportional to the current density. Three-dimensional (3D) digital microscopy showed that, as the DC current increased, the depth of the corrosion pit also increased (gradually), indicating a higher corrosion degree. The sample in the cathode region only underwent a hydrogen evolution reaction, which caused cathodic disbondment of the coating. The stray current had a critical current density for the coating disbonding: the coating delamination area reached its maximum and then remained unchanged.
\end{abstract}

Keywords: X80 pipeline steel; coating damage; DC stray current; anodic corrosion; cathodic disbondment

\section{Introduction}

Due to the complexity of the coating process and mechanical damage during construction, pipeline coatings will inevitably be damaged and/or destroyed. These coatings are also severely affected by various long-term corrosion factors in the soil during the life of the pipe and its service, and these factors often cause coating disbonding. Corrosive media, such as soil solutions, infiltrate into the interface between the pipeline and the damaged coating, forming a favorable corrosion microenvironment and corroding the pipeline [1,2]. Stray currents refer to the currents that occur outside of a specific loop. Stray currents accelerate pipeline corrosion and are one of the most important factors affecting corrosion-related leakage of buried metal pipelines [3,4]. Stray current interference is typically divided into alternating current (AC) and direct current (DC). Corrosion caused by DC is considered to be the most serious [5,6], and a lot of research efforts are dedicated to this issue. Berziou et al. [7] summarized major characteristics of corrosion caused by a DC stray current: the corrosion intensity is high and is localized. Cui et al. [8] used the BEASY software to simulate DC interference with a negative protection system under different soil resistivity conditions as well as its influence on the failure rates of corrosion protection layers and anode parameters. Cheng et al. [9] analyzed the mechanism and drastic influence 
of stray current corrosion on buried metal pipelines in a subway and discussed potential measures to minimize and eliminate the influences of stray current corrosion. Zhu et al. [10] proposed an effective stray current drainage method based on the mechanism of stray current interference to minimize corrosion. Currently, scientists have a good agreement on the mechanism by which DC stray currents cause corrosion, i.e., that it is caused by an electrochemical reaction and the amount of corrosion is proportional to the stray current's density, which follows Faraday's law of electrolysis [11-13].

The main focus of the research efforts is whether or not the buried pipelines experience DC interference and the resulting corrosive damage. However, cathodic disbondment of the coating due to DC stray currents in the pipeline area is less studied. When a DC current passes through the damaged portion of the coating of buried long-distance pipelines, an anode region forms that causes electrolytic corrosion of the metal pipeline, resulting in a corrosion piercing [14,15]. In contrast, DC passing through the cathode region does not cause stray current corrosion of the pipeline because of the protection by the cathode current. However, if the potential of the cathode area is too negative, a cathodic hydrogen evolution reaction (HER) and an oxygen reduction reaction (ORR) occur on the pipeline's surface, causing cathodic disbondment of the coating [16-18]. Nielsen et al. [19], after field investigations and tests, determined that the surface of buried steel pipelines under cathodic protection $(\mathrm{CP})$ generates large amounts of $\mathrm{OH}^{-}$that raise the localized $\mathrm{pH}$ around the defect areas, which eventually leads to a $\mathrm{pH}$ increase in the majority of the area around the buried pipe's coating. Due to the extremely large stray current density in buried pipelines (up to $200 \mathrm{~A} / \mathrm{m}^{2}$ ), delamination of the coating occurs very easily [20]. Therefore, while studying a DC stray current's influence on buried metal pipelines, it is necessary to consider both corrosion of the pipeline and cathodic disbondment of the coating to improve the anticorrosion performance of the organic coatings that protect metal pipelines.

In this work, we used immersion experiments, electrochemical tests, three-dimensional (3D) microscopy, and a surface analysis to study the cathodic disbondment of a polyethylene (3PE) coating caused by the inflow of a DC stray current and the corrosion behavior of the pipeline steel caused by the outflow of a DC stray current in $3.5 \% \mathrm{NaCl}$ solution.

\section{Experimental}

\subsection{Experimental Materials}

The chemical composition of the X80 pipeline steel that was used in this study was $0.06 \mathrm{wt} \%$ of C, 0.216 wt $\%$ of $\mathrm{Si}, 1.80 \mathrm{wt} \%$ of $\mathrm{Mn}, 0.0137 \mathrm{wt} \%$ of $\mathrm{P}, 0.0009 \mathrm{wt} \%$ of $\mathrm{S}, 0.105 \mathrm{wt} \%$ of $\mathrm{Nb}$, and $0.013 \mathrm{wt} \%$ of Ti (Fe balance). A $40 \times 40 \times 2 \mathrm{~mm}^{3}$ sample was machined using a wire-cutting method. After that, the surface of the sample was polished sequentially with SiC60\#, 200\#, 400\#, and 600\# water sandpaper until a uniform metallic luster was obtained and then thoroughly cleaned with ethanol and acetone.

A three-layer structure of polyethylene (3PE) tape was used as a coating material. 3PE supporting primer was evenly applied to the surface of the X80 steel and allowed to dry for 3-5 min. After that, 3PE tape was applied and uniformly pressed to ensure a good bond. Several holes ( $2.5 \mathrm{~mm}$ in diameter) were then drilled through the coating without touching the metal substrate (see Figure 1).

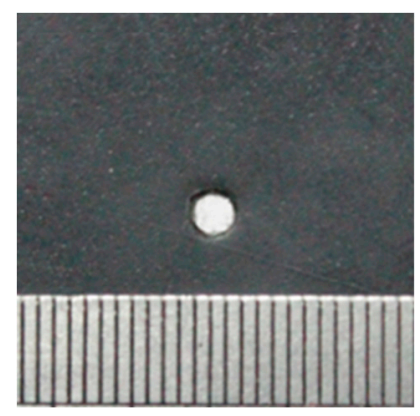

Figure 1. A photograph of prefabricated coating damage points drilled only through the coating (The scale is $1 \mathrm{~mm}$ ). 


\subsection{Electrochemical Test}

A $3.5 \% \mathrm{NaCl}$ solution $(\mathrm{pH}=7$ ) was prepared with analytical reagents and deionized water to simulate the coastal environment. The electrochemical testing and stray current loading device is shown in Figure 2. We used a constant voltage adjustable DC power supply (KXN-305D, Zhaoxin, Shenzhen, Guangdong, China) as a stray current source. $S$ is a switch. $R$ is a resistor. Samples 1 and 2 were connected to the positive and negative electrodes, respectively. A carbon rod was placed in the middle to form a closed circuit. In this configuration, DC flowed out of the damage point of Sample 1 to form an anode metal corrosion area. In contrast, a cathode area formed on Sample 2.

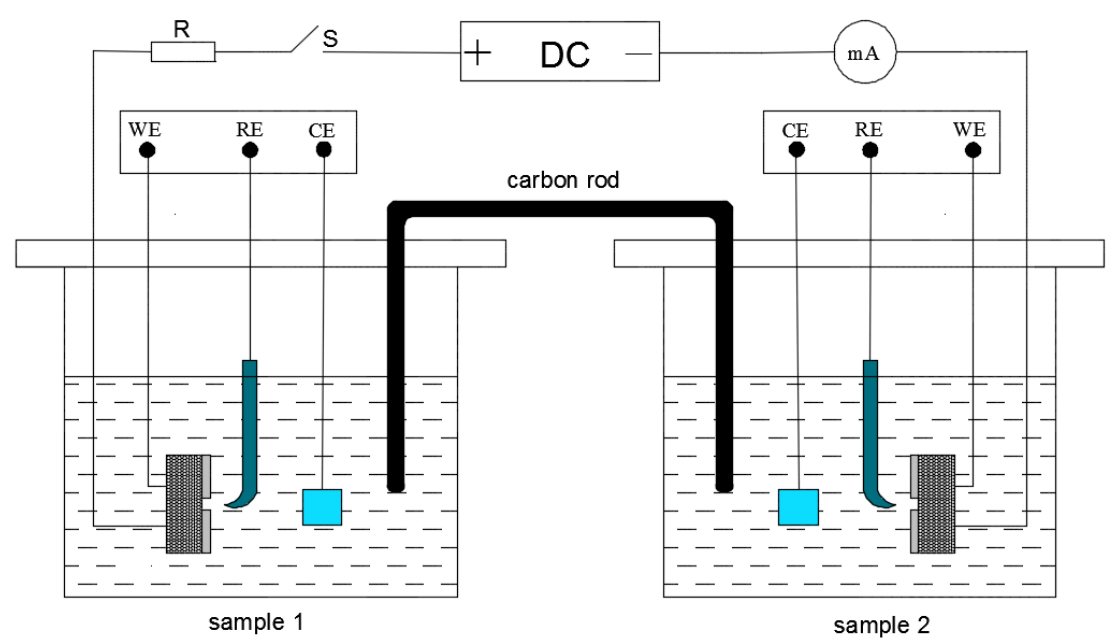

Figure 2. A schematic of the stray direct current (DC) loading and electrochemical testing device. WE, working electrode; RE, reference electrode; CE, counter electrode.

The electrochemical workstation (PARSTAT2273, Hampshire, UK) used a three-electrode system, in which an X80 pipeline steel sample was used as the working electrode (WE), platinum plate was used as a counter electrode (CE), and a saturated calomel electrode (SCE) was used as a reference electrode (RE). Prior to the electrochemical tests, samples were kept for $30 \mathrm{~min}$ in the solution. After that, DCs with different intensities $\left(0,20,40,60,80\right.$, and $\left.100 \mathrm{~A} / \mathrm{m}^{2}\right)$ were applied to test the DC's effect on the corrosion potential of the $\mathrm{X} 80$ steel. After the corrosion potential reached a relatively stable state (within $30 \mathrm{~min}$ ), potential polarization curves were recorded at a $1 \mathrm{mV} / \mathrm{s}$ scan rate. Experimental data were simulated using the Origin software. The corrosion current density $\left(i_{\text {corr }}\right)$ was calculated using the Tafel extrapolation method.

All experimental samples were tested electrochemically and microscopically using a new batch for each analysis. A set of samples was used to analyze the electrochemical kinetic corrosion parameters of X80 steel under DC interference. DC power was applied for $24 \mathrm{~h}$ to another set of samples to analyze the corrosion of X80 steel and the cathodic disbonding morphology of the coating.

\subsection{Analysis of Pitting Corrosion Morphology}

Sample 1 was removed at the end of the experiment. A digital camera (DSC-HX400 Sony, Tokyo, Japan) was then used to record the surface corrosion morphology, after which the 3PE coating was scraped off. The surface was then treated with Clarke's solution containing $1 \mathrm{~L}$ of hydrochloric acid (specific gravity $1.19 \mathrm{~g} / \mathrm{cm}^{3}$ ), $20 \mathrm{~g}$ of antimony trioxide (pure chemical reagent grade), and $50 \mathrm{~g}$ of stannous oxide (pure chemical reagent grade) to remove corrosion products and then washed with deionized water. After drying, the corrosion pit depth was measured using a three-dimensional (3D) digital microscope (HIROX KH-8700, Tokyo, Japan). 


\subsection{Analysis of Cathodic Disbondment Area}

Figure 3 shows a diagram of how the measurements of the cathodic disbondment area of the 3PE coating were performed. Measurements were performed using Sample 2, which was removed from the solution at the end of the experiment. The area around the hole was divided into eight parts (as shown in Figure 3) around the damaged point. The coating was then cut with a knife until the metal substrate became exposed. After that, the knife was inserted into the bottom of the coating from the center of the damaged hole, and the coating was peeled off in the horizontal direction along the cut line until the coating showed significant disbonding resistance. By measuring the distance of each cutting line and the reduced diameter of the damage point, we thus obtained the cathodic disbondment distance, which was then used to calculate the cathodic disbondment area.

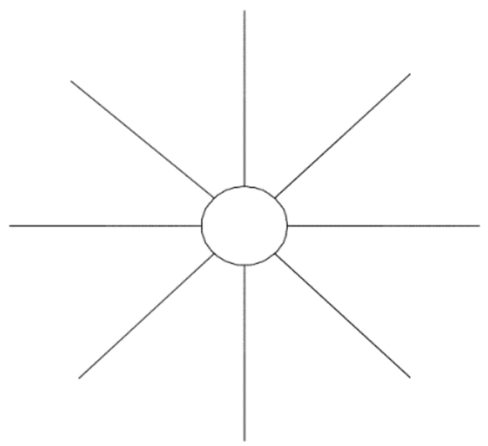

Figure 3. A schematic of the measurement pattern of the cathodic disbondment area of the polyethylene (3PE) coating.

\section{Results and Discussion}

\subsection{Potential Values of the 3PE-Coated X80 Steel in the 3.5\% NaCl Solution under Various DC Current Densities}

When the DC passed through the X80 steel, the balanced electrode reactions became disturbed, causing polarization of the $\mathrm{X} 80$ steel and shifting the electrode potential away from the equilibrium electrode potential. Figure 4a shows potential values of the 3PE-coated X80 steel samples under DC anodic polarization interference at different currents. The potential values shifted positively as the $\mathrm{DC}$ increased. The potential shifted from $-0.68 \mathrm{~V}$ (the value corresponding to the state without DC interference) to $-0.43 \mathrm{~V}$ at $100 \mathrm{~A} / \mathrm{m}^{2}$ of DC interference. Thus, the potential of the X80 steel sample shifted by $0.25 \mathrm{~V}$. Figure $4 \mathrm{~b}$ shows the potential values of 3PE-coated X80 steel under DC cathodic polarization interference at different currents. The potential values shifted negatively as the DC increased: from $-0.68 \mathrm{~V}$ (the value corresponding to the state without DC interference) to $-1.45 \mathrm{~V}$ at $100 \mathrm{~A} / \mathrm{m}^{2}$ of DC current interference. Thus, the potential of the X80 steel shifted by $0.78 \mathrm{~V}$. Therefore, under the same DC conditions, the degree of the cathodic potential shift was greater than that of the anode.

This result agrees with previously reported results. Yang et al. [21] studied the influence of DC stray currents on the surface morphology and electrochemical behavior of X65 steel. They found that, as the DC current density increased, the corrosion potential of the X65 steel also increased, making the X65 steel more susceptible to corrosion. Qian et al. [22] found that, under DC interference, the potential of X52 steel shifted positively and negatively in the anodic and cathodic zones, respectively. The cathodic potential shifts were larger than the anodic ones. 

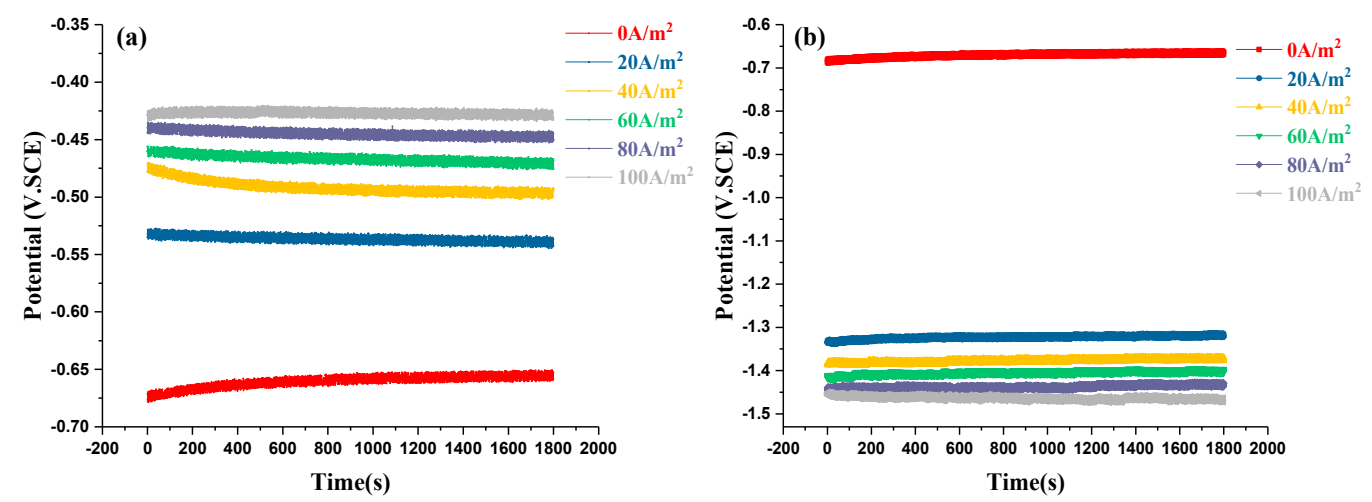

Figure 4. Potential measurements of the results of a 3PE-coated X80 steel sample under DC (a) anode and (b) cathode polarization.

\subsection{Polarization of 3PE-Coated X80 Steel Samples at Different DC Currents}

Figure 5 shows the polarization curves of 3PE-coated X80 steel samples under DC polarization interference at different currents. The kinetic parameters listed in Tables 1 and 2 were obtained by fitting the polarization curves, performed as described elsewhere [23-26]. Bertocci [27] pointed out that the metal corrosion potential shifts under the influence of stray currents, but the direction of this shift depends on the ratio of the absolute values of the Tafel slope between the anode and the cathode $\left(\left|b_{a} / b_{c}\right|\right)$. At $\left|b_{a} / b_{c}\right|=1$, the corrosion potential will not shift. At $\left|b_{a} / b_{c}\right|<1$ or $\left|b_{a} / b_{c}\right|>1$, the corrosion potential will shift negatively or positively, respectively. In general, the DC polarization has a great influence on the Tafel constant. From Figure $5 \mathrm{a}$, it can be seen that, when anode potential is applied to the system, the Tafel constant of the anode and cathode side are obviously changed, and the effect on the cathodic polarization side plot is obviously greater than that of the anode polarization. It can be seen from Figure $5 b$ that, contrary to the direct current anodic polarization, the influence of the direct current cathode on the anodic polarization side plot process of X80 steel is significantly greater than that of the cathodic polarization process.
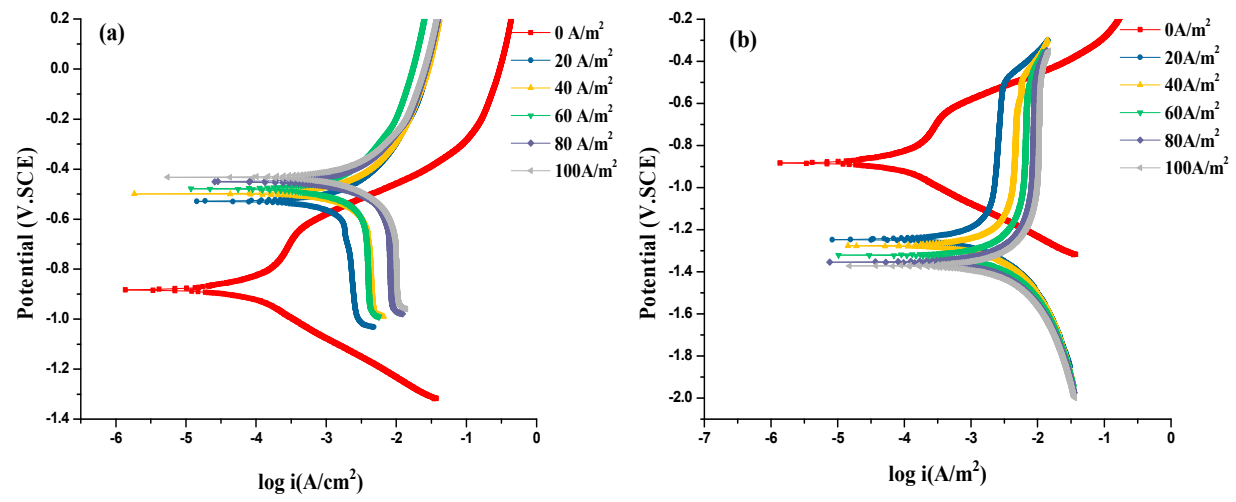

Figure 5. The polarization curves of 3PE-coated X80 steel under DC anode (a) and cathode (b) polarization.

Table 1. The electrochemical parameters of 3PE-coated X80 steel samples under DC anode polarization at different DC current densities.

\begin{tabular}{cccccc}
\hline $\boldsymbol{i}\left(\mathbf{A} / \mathbf{m}^{\mathbf{2}}\right)$ & $\boldsymbol{E}_{\text {corr }}(\mathbf{m V})$ & $\boldsymbol{i}_{\text {corr }}\left(\boldsymbol{\mu A} / \mathbf{c m}^{2}\right)$ & $\boldsymbol{b}_{\mathbf{a}}$ & $\boldsymbol{b}_{\mathbf{c}}$ & $\left|\boldsymbol{b}_{\mathbf{a}} / \boldsymbol{b}_{\mathbf{c}}\right|$ \\
\hline 0 & -859.03 & 36.38 & 69.75 & -150.46 & 0.46 \\
20 & -546.53 & 393.18 & 86.77 & -61.12 & 1.42 \\
40 & -510.55 & 441.99 & 71.73 & -63.51 & 1.13 \\
60 & -470.81 & 478.10 & 94.24 & -85.36 & 1.11 \\
80 & -453.57 & 708.91 & 88.89 & -75.10 & 1.12 \\
100 & -435.26 & 843.20 & 113.56 & -103.06 & 1.10 \\
\hline
\end{tabular}


Table 2. The electrochemical parameters of 3PE-coated X80 steel samples under DC cathode polarization at different DC current densities.

\begin{tabular}{cccccc}
\hline $\boldsymbol{i}\left(\mathbf{A} / \mathbf{m}^{\mathbf{2}}\right)$ & $\boldsymbol{E}_{\text {corr }}(\mathbf{m V})$ & $\boldsymbol{i}_{\text {corr }}\left(\boldsymbol{\mu} \mathbf{A} / \mathbf{c m}^{2}\right)$ & $\boldsymbol{b}_{\mathbf{a}}$ & $\boldsymbol{b}_{\mathbf{c}}$ & $\left|\boldsymbol{b}_{\mathbf{a}} / \boldsymbol{b}_{\mathbf{c}}\right|$ \\
\hline 0 & -858.03 & 36.37 & 69.75 & -150.46 & 0.46 \\
20 & -1247.9 & 213.57 & 57.71 & -68.02 & 0.84 \\
40 & -1256.7 & 381.98 & 53.58 & -86.10 & 0.62 \\
60 & -1324.1 & 612.06 & 50.01 & -122.92 & 0.41 \\
80 & -1357.3 & 875.98 & 53.88 & -159.25 & 0.34 \\
100 & -1352.0 & 982.97 & 58.59 & -186.56 & 0.31 \\
\hline
\end{tabular}

The kinetic parameter $\left|b_{a} / b_{c}\right|$, shown in Table 1 and corresponding to the DC anodic polarization interference conditions, is $>1$; thus, the corrosion potential $E_{\text {corr }}$ shifts positively. Our experimental results also showed that, as the DC current increased, the potential of the X80 steel shifted positively (see Figure 4a). The kinetic parameter $\left|b_{a} / b_{c}\right|$, shown in Table 2 and corresponding to the DC cathodic polarization interference, is $>1$; thus, $E_{\text {corr }}$ shifts negatively. Figure $4 \mathrm{~b}$ confirms this result, as it shows an increase in the DC as the potential of the X80 steel shifted negatively. These results are also consistent with the polarization curve fitting results.

When DC is added to the system, the $E_{\text {corr }}$ and $i_{\text {corr }}$ values change significantly (see Tables 1 and 2). The magnitude of $E_{\text {corr }}$ represents the strength of the electrode polarization potential; $i_{\text {corr }}$ indicates the degree of corrosion and the corrosion rate. The X80 steel demonstrated no passivation in the anode area during the corrosion process. According to Faraday's law of electrolysis [11], the corrosion rate of a metal is directly proportional to the corrosion current density. Thus, the greater the anode corrosion current density, the more obvious the active dissolution tendency of X80 steel is. However, due to the protection of the cathode current, the metal in the cathode region usually does not corrode. At this time, the increase of the cathode corrosion current density represents not the corrosion of the X80 steel but the acceleration of the cathode hydrogen evolution reaction on the surface of the X80 steel metal substrate.

\subsection{Corrosion Morphology and Pitting Corrosion Depth at Different DC Anode Currents}

Because of the 3PE coating, a stray current can only flow out of the damaged coating areas to initiate the electrochemical reaction. The corrosion reactions of X80 steel under the DC anode can be summarized as follows [28]:

$$
\begin{gathered}
\mathrm{Fe} \rightarrow \mathrm{Fe}^{2+}+2 \mathrm{e}^{-} \\
\mathrm{Fe}^{2+}+2 \mathrm{H}_{2} \mathrm{O} \rightarrow \mathrm{Fe}(\mathrm{OH})_{2}+2 \mathrm{H}^{+} \\
4 \mathrm{Fe}(\mathrm{OH})_{2}+\mathrm{O}_{2} \rightarrow 2 \mathrm{Fe}_{2} \mathrm{O}_{3}+4 \mathrm{H}_{2} \mathrm{O}
\end{gathered}
$$

In this paper, since the anode and cathode are separated from each other on the same sample, Sample 1 is the anode region. At the anode area, metallic Fe oxidizes and generates $\mathrm{Fe}^{2+}$ by undergoing an electrolysis reaction and then combines with $\mathrm{H}_{2} \mathrm{O}$ and $\mathrm{O}_{2}$ to oxidize further and to form corrosion products, such as $\mathrm{Fe}_{2} \mathrm{O}_{3}$, which then deposit in the anode region.

When the pipeline is electrochemically corroded by a DC stray current, the metal corrosion complies with Faraday's law:

$$
w=k I t, v=w I / A
$$

where $w$ is the metal corrosion in $\mathrm{g} ; k$ is the electrochemical equivalent of metal in $\mathrm{kg} /(\mathrm{A} \cdot \mathrm{s}) ; I$ is the value of the current flowing out of the anode metal in $A ; t$ is the corrosion duration in $\mathrm{h} ; A$ is the anode metal corrosion area in $\mathrm{cm}^{2}$; and $v$ is the corrosion rate of the metal in $\mathrm{kg} /\left(\mathrm{cm}^{2} \cdot \mathrm{h}\right)$.

Equation (4) can help to estimate damages caused by the DC stray current. Thus, a DC stray current equal to $1 \mathrm{~A}$ can corrode $9.13 \mathrm{~kg}$ of steel in one year [28]. 
Figure 6 shows the depth of the corrosion pits of the X80 steel samples under DC anode interference obtained using three-dimensional (3D) digital microscopy. Figure 7 shows the relationship between the corrosion pit depth and the corresponding current density at the damage point of the coating. The corrosion pits deepened as the DC increased. The depth of the pits represents the severity of the corrosion [29]; thus, in our experiments, the corrosion rate was higher at higher DC current densities, which is in good agreement with Equation (6).
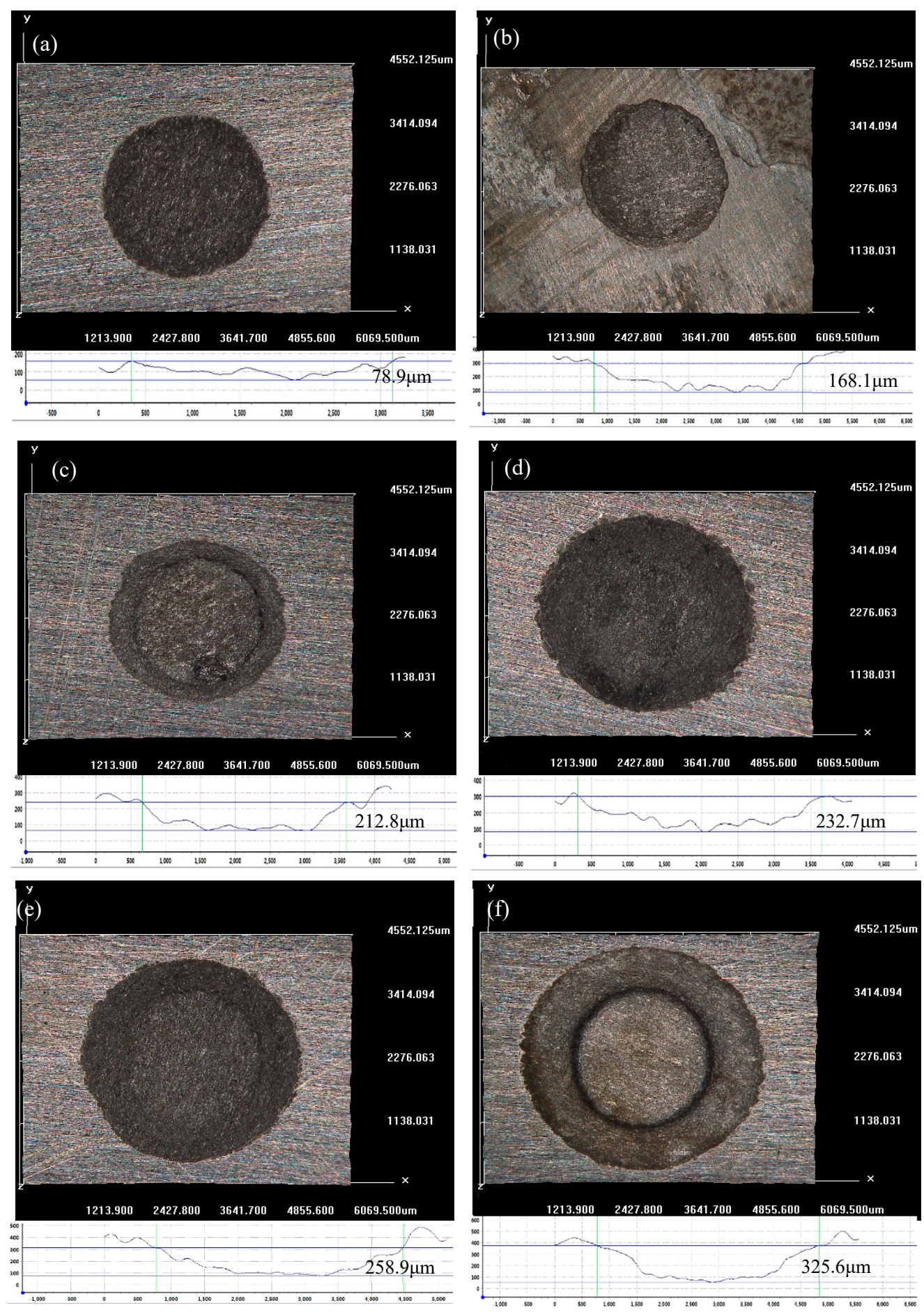

Figure 6. The corrosion pit depth (obtained using three-dimensional (3D) digital microscopy) of the 3PE-coated X80 steel samples at DC anode current densities equal to (a) $0 \mathrm{~A} / \mathrm{m}^{2}$, (b) $20 \mathrm{~A} / \mathrm{m}^{2}$, (c) $40 \mathrm{~A} / \mathrm{m}^{2}$, (d) $60 \mathrm{~A} / \mathrm{m}^{2}$, (e) $80 \mathrm{~A} / \mathrm{m}^{2}$, and (f) $100 \mathrm{~A} / \mathrm{m}^{2}$. 


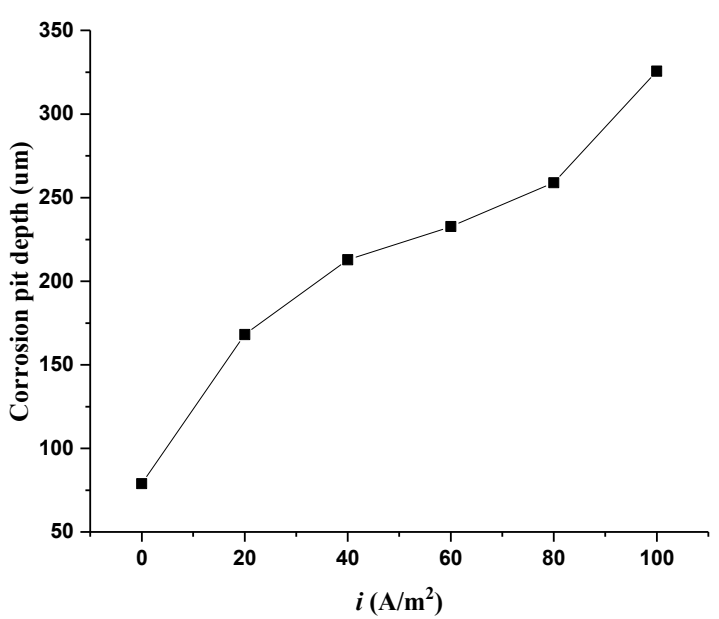

Figure 7. The corrosion pit depth of the 3PE-coated X80 steel samples under DC anode polarization interference with various current densities.

Chen et al. [30] designed and assembled some indoor equipment to simulate DC stray current interference. They noticed that the corrosion rate of the $16 \mathrm{MnR}$ was proportional to the outcoming DC current density in different soil solutions. Wang et al. [31] studied the effect of a stray current on the corrosion of X70 steels with a damaged coating. They pointed out that, as the stray current increased and the coating damage rate decreased, the corrosion rate and the depth of the corrosion pit increased as well, ultimately increasing the corrosion degree. Thus, our results on DC current anode corrosion processes are very consistent with previously reported ones.

\subsection{Cathodic Disbondment of the 3PE Coating from the X80 Steel at Various DC Cathode Currents}

Corrosion of the pipeline in the cathode region does not occur easily. However, if the potential value in the cathode region is extremely negative, HER and ORR occur on the surface of the metal of the pipeline, easily causing the cathodic disbondment of the coating in this region [16]. Sample 2 is a cathode region, and the DC negative electrode supplies electrons that need to be removed during the cathode process, usually by oxygen reduction and/or hydrogen generation. In the cathode area, the cathodic reactions of X80 steel under the action of the DC cathode at the damage of the coating occur as follows [32]:

$$
\begin{aligned}
& \mathrm{O}_{2}+2 \mathrm{H}_{2} \mathrm{O}+4 \mathrm{e}^{-} \rightarrow 4 \mathrm{OH}^{-} \\
& 2 \mathrm{H}_{2} \mathrm{O}+2 \mathrm{e}^{-} \rightarrow \mathrm{H}_{2}+2 \mathrm{OH}^{-}
\end{aligned}
$$

Generally, in aerobic neutral or alkaline solutions, the electrochemical corrosion of metals is called oxygen uptake corrosion, and the cathodic reaction at this time is called an oxygen uptake reaction. However, due to the large stray current in the buried metal pipeline, the cathode potential is negative. As Figure 4 showed, when the current densities were 20 and $40 \mathrm{~A} / \mathrm{m}^{2}$, the reaction potentials were lower than the standard potential of HER $\left(E_{\mathrm{V}, \mathrm{SCE}}=-1.056 \mathrm{~V}\right.$ [33]). Therefore, cathodic reactions of stray currents are dominated by the hydrogen evolution reactions.

Figure 8 shows cathodic disbondment of the 3PE coating of the X80 steel samples caused by a DC stray current. Figure 9 demonstrates the relationship between the cathodic disbondment area and the stray current density. During our experiments, we observed a large number of bubbles at the damaged areas. We speculate that the cathodic reaction of stray currents generated both $\mathrm{H}_{2}$ and $\mathrm{OH}^{-}$ ions. However, the hydrogen evolution process dominated, weakening adhesion between the coating and the metal substrate and leading to the coating delamination. The delamination area of the coating first increased as the initial stray current increased but then stabilized and remained unchanged. Thus, stray current has a critical current density value for the disbonding failure of the buried metal pipeline coating. When the stray current density is less than its critical value, the peel area of the coating varies 
with the current density. When the stray current density is greater than its critical value, delamination area of organic coatings remains unchanged as the current density changes. Cao [34] observed the same behavior of the disbondment as a function of the DC current density even though his experiments were performed under different conditions.
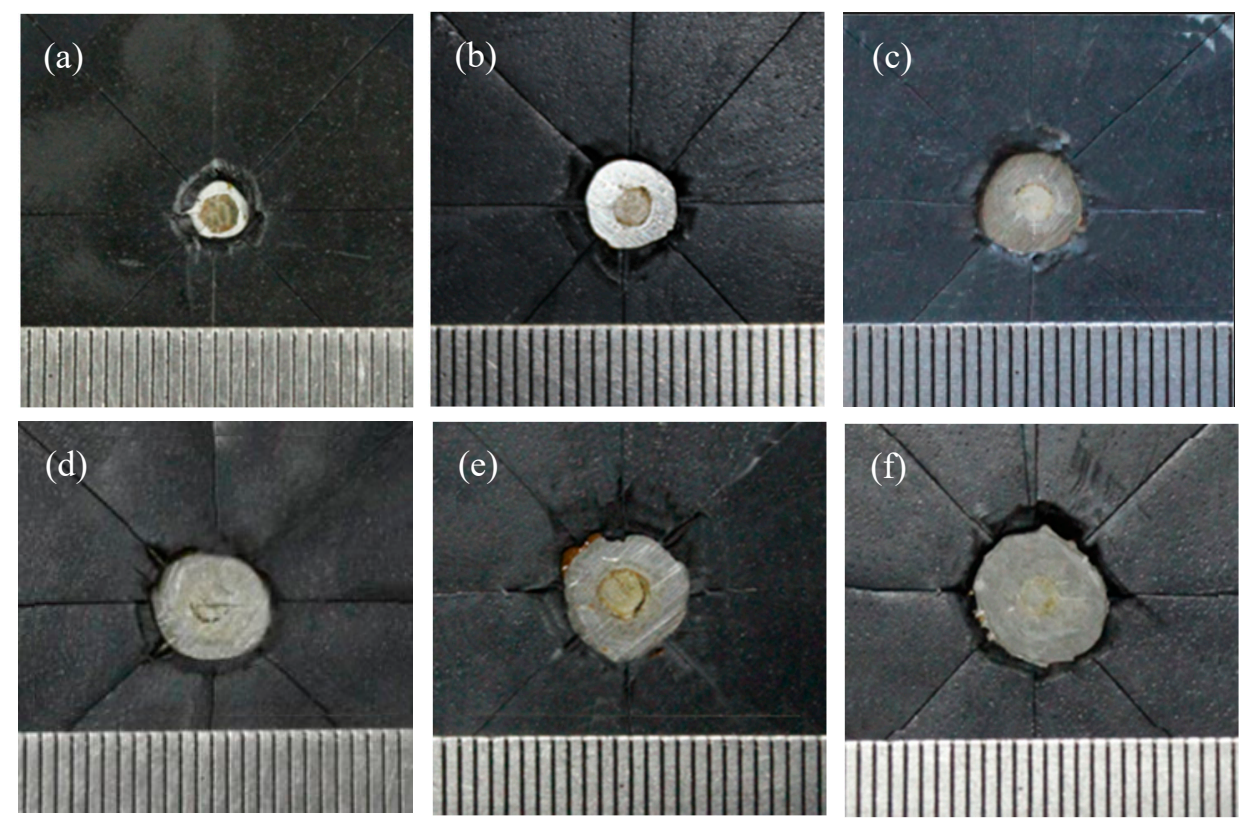

Figure 8. Photographs of the cathodic disbondment of the 3PE coating of the $\mathrm{X} 80$ steel samples under DC cathode current densities equal to (a) $0 \mathrm{~A} / \mathrm{m}^{2}$, (b) $20 \mathrm{~A} / \mathrm{m}^{2}$, (c) $40 \mathrm{~A} / \mathrm{m}^{2}$, (d) $60 \mathrm{~A} / \mathrm{m}^{2}$, (e) $80 \mathrm{~A} / \mathrm{m}^{2}$, and (f) $100 \mathrm{~A} / \mathrm{m}^{2}$.

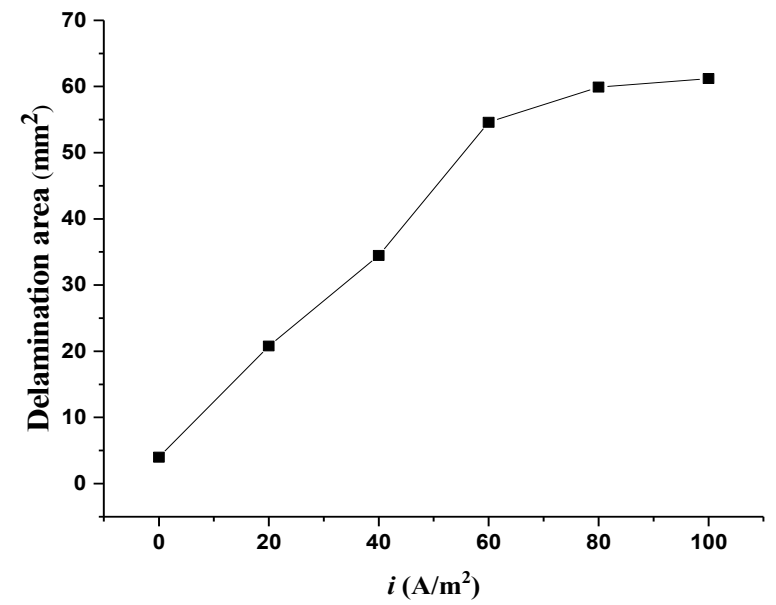

Figure 9. Cathodic disbondment of the 3PE coating of the $\mathrm{X} 80$ steel samples as function of the DC current density under DC cathode polarization.

\subsection{Corrosion and Cathodic Disbondment Mechanism of the Pipeline under the Action of the DC Stray Current}

From our and previously reported literature data, the following mechanism of the corrosion and organic cathodic disbondment of the pipeline under the action of a DC stray current in neutral environments $[35,36]$ can be proposed (see Figure 10). 

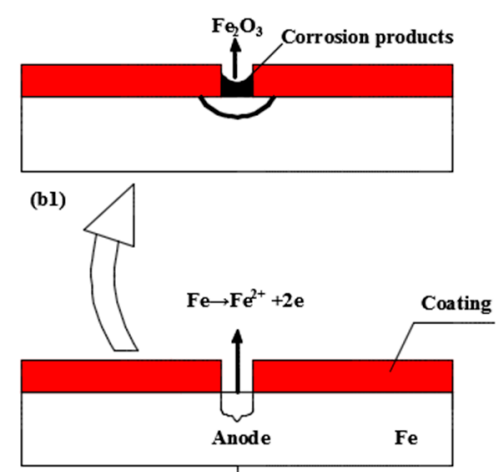

(al)
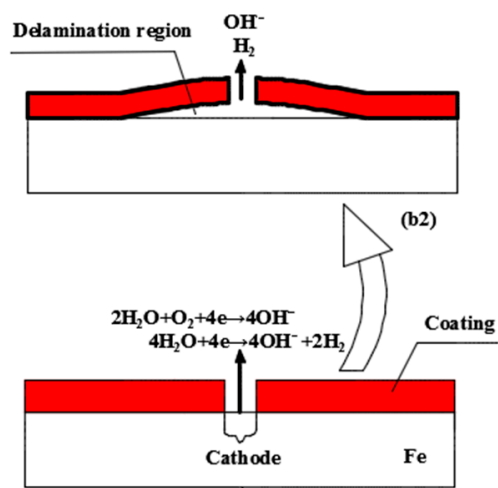

(a2)

Figure 10. A schematic of the corrosion and organic cathodic disbondment mechanism of the pipeline under the DC stray current conditions.

Under a DC stray current, the iron in the anode region generates $\mathrm{Fe}^{2+}$ through the electrolysis reaction (see Figure 10a), which then reacts with $\mathrm{H}_{2} \mathrm{O}$ and $\mathrm{O}_{2}$ to be further oxidized into $\mathrm{Fe}_{2} \mathrm{O}_{3}$ (see Figure 10b) and deposited in the anode region. The damage point is rapidly covered by the corrosion product as the reaction continues, which causes the anode reaction to spread to the surrounding areas. Due to the electrolysis of the direct current, the corrosion pit will expand in both directions at the point of damage of the coating. Longitudinal expansion results in thinning of the tube wall, manifesting as corrosion perforation. Lateral expansion causes the metal matrix under the coating to dissolve, manifesting as anode destruction of the coating.

ORR and dominating HER occur in the stray current cathode region, producing $\mathrm{H}_{2}$ and $\mathrm{OH}^{-}$ions. Driven by the electrostatic forces, $\mathrm{H}_{2}$ and $\mathrm{OH}^{-}$migrate between the interface of the organic coating and the metal substrate forming bubbles and an alkaline environment that weaken the adhesion between the coating and the metal substrate and eventually lead to the cathodic disbondment of the coating.

\section{Conclusions}

Under the effect of a DC stray current, the balance of the electrode reaction becomes interrupted, causing polarization of the X80 steel. The potentials of the X80 steel move in the positive direction during anodic polarization and in the negative direction during the cathode polarization process. At the same DC interference level, the potential deviation of the cathode is greater than that of the anode.

No passivation of the X80 steel occurs during the DC anodic corrosion process. The corrosion process of the pipeline steel follows Faraday's law of electrolysis: the corrosion amount and corrosion rate are proportional to the current intensity. Three-dimensional (3D) digital microscopy showed that the corrosion pit depths increase as the DC stray current increases. At the same time, the X80 steel in the cathode region does not corrode. However, due to the negative cathodic potential, the cathodic reaction is dominated by hydrogen evolution, resulting in the cathodic disbondment of the protective coating.

The cathodic disbondment area of the coating increases as the DC cathode current increases, and a critical current density of the DC cathode current exists. When the stray current density is less than the critical current density, the coating delamination area changes with the current density. However, if the stray current density is greater than the critical value, the delamination area of the coating does not change substantially with the change of the current density.

Author Contributions: Conceptualization, X.W. and Y.C.; Methodology, X.W. and Z.W.; Software, Z.W.; Validation, Y.C.; Formal Analysis, Y.C. and X.S.; Investigation, X.W.; Resources, X.W.; Data Curation, Y.C.; Writing-Original Draft Preparation, Z.W.; Writing-Review and Editing, Y.Y.; Visualization, X.S.; Supervision, Y.C.; Project Administration, X.W.; Funding Acquisition, X.W. and Y.C. 
Funding: This research was funded by the National Natural Science Foundation of China (No. 51471011) and the "Rixin Scientist" of the Beijing University of Technology.

Conflicts of Interest: The authors declare no conflict of interest.

\section{References}

1. Chen, Z.; Qin, C.; Tang, J.; Zhou, Y. Experiment research of dynamic stray current interference on buried gas pipeline from urban rail transit. J. Nat. Gas Sci. Eng. 2013, 15, 76-81. [CrossRef]

2. Cole, I.S.; Marney, D. The science of pipe corrosion: A review of the literature on the corrosion of ferrous metals in soils. Corros. Sci. 2012, 56, 5-16. [CrossRef]

3. Bertolini, L.; Carsana, M.; Pedeferri, P. Corrosion behaviour of steel in concrete in the presence of stray current. Corros. Sci. 2007, 49, 1056-1068. [CrossRef]

4. Gummow, R.A.; Wakelin, R.G.; Segall, S.M. AC corrosion-A new challenge to pipeline integrity. Mater. Perform. 1998, 38, 24-31.

5. Wen, C.; Li, J.; Wang, S.; Yang, Y. Experimental study on stray current corrosion of coated pipeline steel. J. Nat. Gas Sci. Eng. 2015, 27, 1555-1561. [CrossRef]

6. Solgaard A.O.S.; Carsana, M.; Geiker, M.R.; Küter, A.; Bertolini, L. Experimental observations of stray current effects on steel fibres embedded in mortar. Corros. Sci. 2013, 74, 1-12. [CrossRef]

7. Berziou, C.; Remy, K.; Billard, A.; Creus, J. Corrosion behaviour of dc magnetron sputtered $\mathrm{Fe}_{1-x} \mathrm{Mg}_{x}$ alloy films in $3 \mathrm{wt} \% \mathrm{NaCl}$ solution. Corros. Sci. 2007, 49, 4276-4295. [CrossRef]

8. Cui, G.; Li, Z.; Yang, C.; Wei, X. Study on the interference corrosion of cathodic protection system. Corros. Rev. 2015, 33, 233-247. [CrossRef]

9. Cheng, S.; Zhang, L.; Yang, A. Influence of subway stray current corrosion on buried metal pipeline. Gas Heat 2003, 23, 435-437.

10. Zhu, Q.; Cao, A.; Wang, Z.; Song, J.; Shengli, C. Stray current corrosion in buried pipeline. Anti-Corros. Methods Mater. 2011, 58, 234-237. [CrossRef]

11. Shi, Z.; Liu, M.; Atrens, A. Measurement of the corrosion rate of magnesium alloys using Tafel extrapolation. Corros. Sci. 2010, 52, 579-588. [CrossRef]

12. Song, Y.W.; Wang, X.H.; Ren-Yang, H.E.; He, C.F.; Wang, X.Y. Status in research on stray-current corrosion of buried steel pipelines. Corros. Prot. 2009, 8, 003.

13. Zaboli, A.; Vahidi, B.; Yousefi, S.; Hosseini-Biyouki, M.M. Evaluation and control of stray current in DC-electrified railway systems. IEEE Trans. Veh. Technol. 2017, 66, 974-980. [CrossRef]

14. Goidanich, S.; Lazzari, L.; Ormellese, M. AC corrosion-Part 1: Effects on overpotentials of anodic and cathodic processes. Corros. Sci. 2010, 52, 491-497. [CrossRef]

15. Xiao, Y.; Du, Y.; Ou, L.; Sun, H. Influence of environment and coating defects on AC corrosion of pipeline steel. Corros. Sci. Prot. Technol. 2017, 29, 645-650.

16. Martinez, S.; Žulj, L.V.; Kapor, F. Disbonding of underwater-cured epoxy coating caused by cathodic protection current. Corros. Sci. 2009, 51, 2253-2258. [CrossRef]

17. Mahdavian, M.; Naderi, R.; Peighambari, M.; Hamdipour, M.; Haddadi, S.A. Evaluation of cathodic disbondment of epoxy coating containing azole compounds. J. Ind. Eng. Chem. 2014, 21, 1167-1173. [CrossRef]

18. Pedeferri, P. Cathodic protection and cathodic prevention. Construct. Build. Mater. 1996, 10, $391-402$. [CrossRef]

19. Nielsen, L.; Galsgaard, F. Sensor technology for on-line monitoring of AC induced corrosion along pipelines. In Proceedings of the Corrosion 2005, Houston, TX, USA, 3-7 April 2005.

20. Ormellese, M.; Goidanich, S.; Lazzari, L. Effect of AC interference on cathodic protection monitoring. Corros. Eng. Sci. Technol. 2011, 46, 618-623. [CrossRef]

21. Yang, C.; Cui, G.; Zi-Li, L.I.; Cheng-Bin, Z.; Ya-Lei, Z. Effects of direct stray current on surface morphology and electrochemical behavior of X65 steel. Mater. Prot. 2016, 49, 18-22. (In Chinese)

22. Qian, S.; Cheng, Y.F. Accelerated corrosion of pipeline steel and reduced cathodic protection effectiveness under direct current interference. Constr. Build. Mater. 2017, 148, 675-685. [CrossRef]

23. Walter, G.W.; Madurasinghe, M.A.D. Corrosion rates from low polarization data calculated by a galvanostatic, non-linear curve fitting method. Corros. Sci. 1989, 29, 1039-1055. [CrossRef] 
24. Bellezze, T.; Giuliani, G.; Roventi, G. Study of stainless steels corrosion in a strong acid mixture. Part 1: Cyclic potentiodynamic polarization curves examined by means of an analytical method. Corros. Sci. 2017, 130, 113-125. [CrossRef]

25. Mansfeld, F. Tafel slopes and corrosion rates obtained in the pre-Tafel region of polarization curves. Corros. Sci. 2005, 47, 3178-3186. [CrossRef]

26. Bellezze, T.; Giuliani, G.; Viceré, A.; Roventi, G. Study of stainless steels corrosion in a strong acid mixture. Part 2: Anodic selective dissolution, weight loss and electrochemical impedance spectroscopy tests. Corros. Sci. 2017, 130, 12-21. [CrossRef]

27. Bertocci, U. AC induced corrosion. The effect of an alternating voltage on electrodes under charge-transfer control. Med. Sci. Sports Exerc. 2000, 32, 1281-1287. [CrossRef]

28. Guo, Y.; Tan, H.; Meng, T.; Wang, D.; Liu, S. Effects of alternating current interference on the cathodic protection for API 5L X60 pipeline steel. J. Nat. Gas Sci. Eng. 2016, 36, 414-423. [CrossRef]

29. Wang, Y.; Yan, Y.G.; Dong, C.F.; Qian, J.; Li, X. Effect of stray current on corrosion of Q235, 16 Mn and X70 steels with damaged coating. Corros. Sci. Prot. Technol. 2010, 22, 117-119.

30. Chen, X.; Liu, H.; Chen, Z.; Wu, C.; Chen, H.; Wang, W.; Liu, L. ICPTT 2012-Simulation evaluation of dc interference current corrosion based on outflowing current density in different soil. In Proceedings of the American Society of Civil Engineers International Conference on Pipelines and Trenchless Technology, Wuhan, China, 19-22 October 2012; pp. 101-112.

31. Wang, X.; Xu, C.; Chen, Y.; Tu, C.; Wang, Z.; Song, X. Effects of stray AC on corrosion of 3-layer polyethylene coated X70 pipeline steel and cathodic disbondment of coating with defects in $3.5 \mathrm{wt}-\% \mathrm{NaCl}$ solution. Corros. Eng. Sci. Technol. 2018, 53, 214-225. [CrossRef]

32. Fu, A.Q.; Cheng, Y.F. Effect of alternating current on corrosion and effectiveness of cathodic protection of pipelines. Can. Metall. Q. 2012, 51, 81-90. [CrossRef]

33. Chen, Y. Electrochemical impedance spectroscopy study for cathodic disbondment test technology on three layer polyethylene anticorrosive coating under full immersion and alternating dry-wet environments. Int. J. Electrochem. Sci. 2016, 11, 10884-10894. [CrossRef]

34. Cao, A.L. Research on Stray Current Corrosion Protection of Buried Metal Pipelines. Ph.D. Thesis, Chongqing University, Chongqing, China, 2010. (In Chinese)

35. Qian, S.; Cheng, Y.F. Degradation of fusion bonded epoxy pipeline coatings in the presence of direct current interference. Prog. Org. Coat. 2018, 120, 79-87. [CrossRef]

36. Mahdavi, F.; Tan, M.J.; Forsyth, M. Electrochemical impedance spectroscopy as a tool to measure cathodic disbondment on coated steel surfaces: Capabilities and limitations. Prog. Org. Coat. 2015, 88, 23-31. [CrossRef]

(C) 2019 by the authors. Licensee MDPI, Basel, Switzerland. This article is an open access article distributed under the terms and conditions of the Creative Commons Attribution (CC BY) license (http://creativecommons.org/licenses/by/4.0/). 